\title{
OS MÉTODOS DE INVESTIGAÇÃO E EXPOSIÇÃO EM MARX E A PESQUISA NO CAMPO EDUCACIONAL
}

\author{
LOS MÉTODOS DE INVESTIGACIÓN Y EXPOSICIÓN EN MARX Y LA \\ INVESTIGACIÓN EN EL CAMPO EDUCATIVO
}

\section{THE METHODS OF INVESTIGATION AND EXPOSURE IN MARX AND RESEARCH IN THE EDUCATIONAL FIELD}

DOI: https://doi.org/10.9771/gmed.v13i3.45404

\author{
Hedgard Rodrigues Silva ${ }^{1}$ \\ Jorge Fernando Hermida²
}

\begin{abstract}
Resumo: Baseado no método de pesquisa marxista, o artigo aborda especificamente os métodos de investigação e exposição presentes na proposição do materialismo histórico-dialético, com o objetivo de apresentar suas contribuições para a pesquisa no campo educacional. Os esforços de reflexão e síntese teórica são resultado de pesquisa bibliográfica fundamentada na perspectiva dialética, no sentido de expor elementos centrais dos processos dos métodos de investigação e de exposição. Infere que, diante dos métodos de investigação e exposição de fundamentação marxista, as pesquisas no campo educacional podem contribuir para elucidar fenômenos educacionais que visem compreender e transformar as determinações políticas, ideológicas, históricas e sociais.
\end{abstract}

Palavras-chave: Materialismo histórico e dialético. Metodologia da pesquisa. Método de investigação. Método de exposição. Marxismo.

Resumen: Basado en el método de investigación marxista, el artículo aborda específicamente los métodos de investigación y exposición presentes en la propuesta del materialismo histórico-dialéctico, con el objetivo de presentarsus aportes a la investigación em el campo educativo. Los esfuerzos de reflexión y síntesis son el resultado de una investigación bibliográfica basada en la perspectiva dialéctica, com el sentido de exponer los procesos de investigación y métodos de exposición. Se infiere, que, dados los métodos de investigación y exposición de fundamentos marxistas, las investigaciones en el campo educativo pueden contribuir a dilucidar los fenómenos educativos que visen comprender y transformar las determinaciones políticas, ideológicas, históricas y sociales.

Palabras clave: Materialismo histórico y dialéctico. Metodologia de la investigación. Método de investigación. Método de exposición. Marxismo.

Abstract: Based on the Marxist research method, the article specifically addresses the methods of investigation and exposition present in the proposition of historical-dialectical materialism, with the aim of presenting its contributions to research in the educational field. The efforts at theoretical reflection and synthesis are the result of bibliographical research based on a dialectical perspective, in order to expose central elements of the processes of investigation and exposition methods. It infers that, given the methods of investigation and exposition of Marxist foundations, research in the educational field can contribute to elucidate educational phenomena that aim to understand and transform political, ideological, historical and social determinations.

Key words: Historical and dialectical materialism. Research methodology. Research method. Exposure method. Marxism.

\section{Introdução}


Entretanto, o antagonismo entre o proletariado e a burguesia é uma luta de uma classe contra outra, uma luta que, levada à sua mais alta expressão, é uma revolução total. Ademais, é de provocar espanto que uma sociedade fundada na oposição de classes conduza à contradição brutal, a um choque corpo a corpo como derradeira solução?

Não digam que o movimento social exclui o movimento político. Não há jamais um movimento político que não seja ao mesmo tempo social.

Somente numa ordem de coisas em que não houver mais classes e antagonismo de classe as evoluções sociais deixarão de ser revoluções políticas. Até lá, às vésperas de cada reorganização geral da sociedade, a última palavra da ciência social será sempre: "O combate ou a morte, a luta sanguinária ou o nada. É assim que a questão está irresistivelmente posta" (George Sand).

(Miséria da filosofia, KARL MARX, itálico do original)

Um grande desafio de todo pesquisador é a definição do método de pesquisa para alcançar a resposta ao problema de investigação. Organizar o caminho para se chegar ao objetivo da pesquisa é uma tarefa que requer um olhar cuidadoso sobre o objeto de estudo e uma definição compreensiva da problemática de pesquisa. Nas Ciências Humanas e Sociais, a escolha do método de pesquisa é determinada pela natureza do próprio objeto de estudo. Estabelecida essa unidade básica, o método de pesquisa passa a orientar todo o trabalho e sua interpretação do mundo a partir de determinada perspectiva, pois a pesquisa científica se utiliza de estratégias de investigação fundamentadas em "uma rede de pressupostos ontológicos e da natureza humana que definem o ponto de vista que o pesquisador tem do mundo que o rodeia" (RICHARDSON, 1999, p. 32).

A partir da preocupação com a pesquisa no campo educacional, nos debruçamos sobre a metodologia da pesquisa na perspectiva do materialismo histórico e dialético, e sobre as especificidades que caracterizam a passagem do método de investigação ao método de exposição nesta concepção teórica e metodológica, sabendo que os estudos sobre a educação podem ser realizados sob diferentes ângulos de perspectivas e matizes teóricos, podendo ser observada, ou melhor, problematizada em diversos aspectos.

Refletir sobre a educação sob a perspectiva marxista é pensar sobre os processos sociais de formação do ser humano que ocorrem em diversos ambientes. A educação, enquanto prática de formação humana e social consiste na criação da realidade histórica, submetida a determinações econômicas, sociais, políticas e ideológicas, pois compõe a superestrutura em conjunto com outros elementos da cultura, alinhada à demanda de construção e reprodução de processos sociais hegemônicos. No entanto, a dinâmica e a complexidade que caracterizam a vida social requerem dos cientistas sociais um olhar crítico da realidade, ancorado na categoria da contradição. Concordamos, pois, com o epistemólogo Silvio Ancízar Sánchez Gamboa quando ele nos diz que “(...) a educação também é espaço de reprodução das contradições que dinamizam as mudanças e possibilitam a gestação de novas formações sociais" (GAMBOA, 2010, p.115).

A pesquisa no campo educacional precisa estar atenta à realidade que envolve a formação do ser humano em suas perspectivas de particularidade e universalidade, e voltar sua atenção à totalidade que a inscreve. Há uma série de possibilidades para a lente que se observa os processos educativos e é diante dessa abundância de tendências investigativas que este trabalho encontra sua problemática norteadora. 
As direções metodológicas estão cada vez mais abundantes. Triviños (2009) apresentou como correntes do pensamento que orientavam a educação e as pesquisas em ciências sociais o positivismo, a fenomenologia e o marxismo. Consideramos a matriz epistémica proposta por esse autor uma das mais antigas e a partir da qual se desdobram outras possibilidades metodológicas, variadas e diversas, que visam garantir especificidades de um mundo em constantes transformações.

Com a "crise" instaurada nas Ciências Sociais nas últimas décadas, em certos setores intelectuais tornou-se comum afirmar que as Ciências Sociais atravessam uma crise sem precedentes, na qual metanarrativas que fundamentaram grandes sistemas teóricos passam a ser sumariamente desqualificadas, pelo simples fato de serem consideradas por esses setores intelectuais pensamentos racionalistas ultrapassados (EVANGELISTA, 1997). Se as Ciências Sociais e seus paradigmas científicos clássicos (advindos da emergência e consolidação da formação social capitalista) foram considerados a expressão de um processo civilizatório destinado a reger a vida humana no planeta, as duas guerras mundiais, a libertação das colônias, as revoluções socialistas na Rússia e na China, o holocausto nazifascista, a destruição do meio ambiente e a ameaça da eliminação da humanidade pelo holocausto nuclear desenvolveram um movimento de questionamento e contestação dos próprios limites da modernidade (SANTOS, 1999). Para o paradigma emergente da pós-modernidade, a ideia de progresso ou emancipação universal ancorada em noções clássicas de verdade, razão, identidade e objetividade caem por terra, para dar espaço a uma outra forma de conceber o real, baseadas no contingente, diverso, instável e imprevisível (EAGLETON, 1998).

Diante do irracionalismo pós-moderno em que se instaura na incognoscibilidade e relatividade para todo o conhecimento com validade de infinitas interpretações, tomadas de maneira fragmentada, o que ocorre é a negação do marxismo como afirmação crítica que se coloca na perspectiva de totalização de síntese da realidade. Como afirmou Evangelista (1997, p. 31): “o marxismo, ao contrário dessas outras concepções, reivindica para si a condição de pensamento totalizante e integralizador, reconhecendo-se como herdeiro e continuador das grandes sínteses do pensamento moderno".

A crise de paradigmas das Ciências Sociais também teve desdobramentos específicos no campo educacional em geral e na pesquisa educacional desenvolvida nos cursos de pós-graduação em particular. A localização e o respaldo às pesquisas de fundamentação marxista nos cursos de pós-graduação em educação encontraram dificuldades na expansão das ideias e na execução da práxis pedagógicas de acesso a compreensão crítica da realidade, sobretudo quando a teoria social marxista e as virtudes do seu método crítico-dialético passam a marcar presença relevante na produção de conhecimentos que evidenciam as limitações do sistema social predominante (o capitalismo) na resolução dos problemas que ele mesmo cria e que é incapaz de solucionar. Nessa perspectiva, os atributos de um método (o materialismo histórico e dialético) cujas categorias centrais - a dialética, a contradição, a totalidade, a luta de classes, o movimento, a mudança social e a emancipação humana - se colocam a favor da classe trabalhadora e de outras classes subalternas que compõem as sociedades classistas. Especialmente, se considerarmos a conjuntura política atual, quando o país precisa urgentemente de ações políticas e raciocínios críticos que ajudem à classe trabalhadora no enfrentamento à política de extrema direita neoconservadora e ultraliberal, irascível, 
genocida, fascista e nefasta - inclusive ao planeta, cuja política ambiental nada mais é do que a extensão de uma agenda econômica perversa que só visa o lucro acima de tudo e acima de todos. Extermínio de povos indígenas, perseguição às populações nativas, desmatamentos na floresta amazônica como nunca visto, queimadas massivas no Pantanal e na Amazônia, dentre outras tantas agressões irreversíveis ao meio ambiente, ao pulmão do mundo que é a Amazônia.

$\mathrm{Na}$ medida em que o sistema prossegue condenando segmentos crescentes das sociedades contemporâneas à exploração e a todas as formas de opressão - com suas sequelas de pobreza, marginalidade e exclusão social - e agredindo sem pausa a natureza mediante a brutal mercantilização da água, do ar e da terra, as condições de base que exigem uma visão alternativa da sociedade e uma metodologia prática para pôr fim a esta ordem de coisas seguiram estando presentes, todo o qual não faz senão ratificar a renovada vigência do marxismo. (BORON, 2007, p. 29)

As virtudes de uma teoria do conhecimento dotada de procedimentos metodológicos que contribuem para a apreensão e compreensão do real levaram o filósofo existencialista Jean Paul Sartre a posicionar-se em seu favor. Na sua obra clássica intitulada Crítica da razão dialética (2002), Sartre afirmou que o marxismo era a "filosofia inevitável do nosso tempo" (SARTRE, 2002). ${ }^{3}$ Importante salientar que os autores deste artigo compartilham desta opinião, mencionando-a em inúmeras palestras, livros e artigos de revistas publicados por muitos especialistas marxistas - a exemplo de Netto e Braz (2011), Lowy (1989), Sánchez Gamboa (2012), Harvey (2013), Gorender (2013) - que dizem respeito ao seguinte: o que Marx se propôs nos seus estudos e pesquisas foi teorizar sobre a ordem social burguesa, sob a dominância do modo capitalista de produção. Nesse sentido, a teoria marxista seria a descrição do movimento real do objeto desse conhecimento. Isto é, a reprodução ideal do movimento real (a sociedade burguesa) e seus movimentos efetivos. O que Marx buscava era, portanto, uma nova inteligibilidade do social, o que fez brilhantemente ao criar os fundamentos para que isso acontecesse.

Segundo Harvey (2013),

O objetivo de Marx n’O Capital é, por meio de uma crítica da economia política, compreender como o capitalismo funciona. Ele sabe que isso será uma empreitada enorme. Para realizar tal projeto, precisa desenvolver um aparato conceitual que o ajude a entender toda a complexidade do capitalismo e, em uma de suas introduções, explica como planeja realizar isso. "Sem dúvida", escreve ele no posfácio à segunda edição, "o modo de exposição tem de se distinguir, segundo sua forma, do modo de investigação". (HARVEY, 2013, p. 17)

A partir da concepção marxista de investigação, organizada nos métodos de investigação e exposição (GORENDER, 2013; CHAGAS, 2011; FERNANDES, 2008; KOSIC, 2002), e da preocupação com a suposta crise de paradigmas no campo das Ciências Sociais, e da pesquisa no campo da educação, este artigo pretende responder à questão norteadora, que foi formulada da seguinte maneira: Quais as contribuições dos métodos de investigação e exposição de viés marxista para a pesquisa no campo educacional? Nessa sequência, o objetivo desse trabalho é apresentar as contribuições metodológicas de inspiração marxista, que colaboram para fundamentar a transposição didática do método de pesquisa da investigação para a exposição no campo educacional em geral e nas políticas educacionais em particular. 
O trabalho aqui apresentado é fruto de estudos, debates e pesquisas que vêm sendo desenvolvidos em um grupo de pesquisa de orientação teórica e metodológica marxista ${ }^{4}$ e em uma disciplina ministrada na forma de tópicos, cujo escopo são a teoria e a metodologia do materialismo histórico e dialético. ${ }^{5}$ Foi nesses âmbitos que os autores deste artigo realizaram um esforço de aproximação e de estudo do método de pesquisa em Marx. Sabe-se que Karl Marx nunca se propôs escrever um livro específico sobre metodologia da pesquisa, ainda que temas vinculados a métodos de pesquisa possam ser localizados em obras pontuais de Marx (Miséria da Filosofia; Grundrisse; O capital) e de Marx e Engels (A sagrada família; A ideologia alemã), já que fundamentos dessa natureza, só de maneira esparsa, se encontra no conjunto de sua obra. Os esforços de reflexão e de sistematização teórica aqui apresentados resultam de pesquisa bibliográfica fundamentada na perspectiva dialética. Na opinião dos autores deste artigo, esse método é o mais adequado para realizar a apropriação de conceitos e tecer considerações sobre os métodos de investigação e exposição em Karl Marx.

Após esta breve introdução para situar a questão norteadora, o objetivo e a justificativa do estudo, tendo em vista a atualidade e a importância do método de pesquisa marxista, apresentaremos, em seguida, um apanhado inicial de suas principais características para, na continuação do texto, enveredarmos para a compreensão dos métodos de investigação e exposição de acordo com o arcabouço teórico crítico contido nas obras clássicas que tratam sobre o tema. O domínio conceitual conduz para a realização de reflexões a respeito da produção do conhecimento no campo da educação. Por fim, o texto se encerra com a apresentação das considerações finais, onde esboçamos uma síntese dos principais achados deste artigo e onde levantamos outros questionamentos e/ou problemas em aberto, passíveis de serem estudados e pesquisados pelos autores deste texto, mas também por outros autores que, identificados com a temática, queiram dar continuidade aos estudos aqui apresentados.

\section{Breves considerações gerais sobre a pesquisa de viés marxista}

O método marxista não foi uma construção direta objetivada por Marx, mas estão presentes em suas obras, passagens que fazem referência a sua maneira de elaboração (MARX, 2008, 2011 e 2013a). Como na perspectiva materialista e dialética a construção tanto da teoria quanto da metodologia é uma tarefa coletiva, passamos a tratar do assunto resgatando não só a principal contribuição do nosso autor principal, mas também do aporte de outros autores que têm a contribuir para o desenvolvimento do tema, como em MARX e ENGELS, 2003 e 2007; BORÓN, 2007; CHAGAS, 2011; DUAYER, 2011; FRIGOTTO, 2010; GAMBOA, 2012; GORENDER, 2013; e KOSIK, 2002.

A análise da teoria social desenvolvida pelo autor comporta momentos distribuídos em diversos textos, que revelam princípios e/ou elementos metodológicos (MARX, 2008, 2011 e 2013a; MARX e ENGELS, 2003 e 2007). São eles que nos permitem caracterizar uma proposta metodológica no conjunto de sua obra. Marx possuía uma forma particular de trabalhar e de estudar que reunia uma gama diversa de matérias que, associadas às matérias de outras áreas (como seus conhecimentos vinculados à filosofia clássica, à economia política e até a obras clássicas da literatura da sua época), agregam valor quantitativo e 
principalmente qualitativo, tendo em consideração o grande volume de material utilizado em suas reflexões. Costumava fazer extrato dos textos de consulta dos principais clássicos da sua época, acompanhado de anotações pessoais, com isso, deixa registrados temas, autores, desdobramentos e a trilha utilizada em suas buscas (DUAYER, 2011).

A multifacetada maneira de escrever e de fazer ciência não tiram méritos a sua proposta metodológica. A forma poética de descrever suas ideias mesclava erudição (ao tentar descrever a infâmia com que os servos eram castigados pelo estado burguês alemão, na sua Crítica da filosofia do direito de Hegel Karl Marx utiliza citações bíblicas, da história do direito, dos conhecimentos histórico e filosófico e da mitologia grega), literatura, contos populares e poesia (como podemos ver n'O Capital, onde encontramos citações de filósofos gregos, Shakespeare, Fausto, Balzac, Shelley junto com relatos de lobisomens e vampiros). Ao falar das virtudes da proposta metodológica contida naquela que se tornaria a principal obra do cientista social alemão, Harvey (2013) afirmou o seguinte:

O capital é, portanto, um texto rico e multidimensional. Ele se move num vasto mundo de experiências, conceitualizado numa grande diversidade de literaturas escritas em muitas línguas, em diferentes lugares e épocas. Não estou dizendo, apresso-me a explicar, que você não será capaz de compreender Marx se não entender todas as referências. Mas o que me inspira, e espero que inspire você, é a ideia de que há nelas uma imensa gama de recursos que podem esclarecer por que vivemos a vida do modo como a vivemos. Da mesma forma que eles foram a água que moveu o moinho da compreensão marxiana, podemos fazer delas a água para mover o nosso próprio moinho. (HARVEY, 2013, p. 12, grifos do autor)

No método fundado por Marx não há regras e procedimentos pré-estabelecidos, assim, não é pretensão desse texto mostrar a perspectiva dos métodos de investigação e exposição como um procedimento de passos técnicos como guias pré-determinados, nem reduzir a pesquisa de fundamentação marxista a um programa ou receita, pois isso o tornaria "gratuitamente pequeno e sem fundamento, dado que como teoria científica e como 'guia para a ação' é muito mais do que uma simples agenda de pesquisa" (BORON, 2007, p. 31).

A dialética materialista é ao mesmo tempo "uma postura, um método de investigação e uma práxis, um movimento de superação e de transformação" (FRIGOTTO, 2010, p. 86). A produção do conhecimento é realizada pela unidade indissolúvel entre a teoria e a ação prática. Essa unidade das distintas dimensões que compõe o processo do conhecimento chama-se práxis, que configura a reflexão teórica sobre e para a ação prática transformadora.

Entendido como perspectiva crítico-dialética é ela quem questiona fundamentalmente a concepção estática da realidade social colocada pelas abordagens empírico-analíticas e fenomenológicohermenêuticas. A propositura marxista lança a crítica dos conflitos de interesses sociais e pauta a transformação dos fenômenos por meio das possibilidades de mudança pelo sujeito histórico (GAMBOA, 2010), mas não nega as abordagens anteriores em sua totalidade, ao contrário, as reintegra, articulando sujeito e objeto em uma relação histórica e dialética para a compreensão da realidade concreta.

Ao refletir sobre as contribuições do método marxista para o desenvolvimento da ciência, Felismino (2004) elaborou a seguinte síntese: 
Permite a explicitação e a compreensão dos fenômenos sociais em suas contradições e em sua relação com a totalidade histórico-social, diferencia o modo de ser da relação sujeito-objeto no processo de conhecimento e se opõe às visões unilaterais; instaura uma nova concepção de método científico com método de investigação, a apropriação analítica do objeto e o método de exposição das determinações fundamentais e as conexões dialéticas do fenômeno com a essência; não possui pressuposto de objetividade lógico subjetivista, mas se situa na prática social dos homens; diferenciam-se por buscar apreender a gênese e o movimento dos fenômenos sociais e mediá-los com as categorias da contradição e da totalidade, imanentes à realidade social; carrega no conhecimento produzido a potencialidade de não apenas desvelar o que o real é, mas também de crítica social que aponte a superação das relações sociais capitalistas. (FELISMINO, 2004, p. 82)

Pensar, refletir e construir pesquisas que visem à compreensão da realidade concreta é premente e indelével na construção de um mundo melhor. Para se alcançar essa compreensão, Kosik (2002) nos lembra que é preciso decompor o todo para se conhecer a estrutura.

O conceito da coisa é compreensão da coisa, e compreender a coisa significa conhecerlhe a estrutura. A característica precípua do conhecimento consiste na decomposição do todo. A dialética não atinge o pensamento de fora para dentro, nem de imediato, nem tampouco constitui uma de suas qualidades; o conhecimento é que é a própria dialética em uma das suas formas; o conhecimento é a decomposição do todo. (KOSIK, 2002, p. 17)

Compreender a totalidade não significa dar conta de tudo que existe no mundo no sentido de explicar a infinidade de fenômenos do presente, passado e futuro, mas está relacionado à compreensão da realidade em suas articulações, sem isolar e tornar independente o objeto, mas apresentar a interação de suas partes no modo de produção, os fatos e as mediações necessárias para compreensão de seu movimento.

A manifestação dos fenômenos relacionados à educação que circulam o cotidiano social com suas aparências imediatas adentra a consciência dos seres humanos de maneira que se alojam como conceitos independentes do complexo social e forma uma representação aparente e superficial da realidade que Kosik (2002) chama de "mundo da pseudoconcreticidade".

O mundo da pseudoconcreticidade é um claro-escuro de verdade e engano. $O$ seu elemento próprio é o duplo sentido. $\mathrm{O}$ fenômeno indica a essência e, ao mesmo tempo, a esconde. A essência se manifesta no fenômeno, mas só de modo inadequado, parcial, ou apenas sob certos ângulos e aspectos. O fenômeno indica algo que não é ele mesmo e vive apenas graças ao seu contrário. A essência não se dá imediatamente; é mediata ao fenômeno e, portanto, se manifesta em algo diferente daquilo que é. A essência se manifesta no fenômeno. $\mathrm{O}$ fato de se manifestar no fenômeno revela seu movimento e demonstra que a essência não é inerte nem passiva. Justamente por isso o fenômeno revela a essência. A manifestação da essência é precisamente a atividade do fenômeno. (KOSIK, 2002, p. 15)

A reprodução aparente dos fenômenos educacionais no cotidiano cria o pensamento comum, fruto da práxis cotidiana e utilitária que orienta o movimento humano guiado nessa aparência, nesse senso comum, que não consolida a apreensão da realidade em sua essência, ou seja, em sua estrutura dinâmica mais profunda, o que impossibilita transformações de caráter mais radical dessa realidade.

A perspectiva da dialética marxista não se contenta com a orientação das práticas sociais da humanidade orientadas no mundo da aparência, mas se propõe a superar essas representações fincadas no pensamento abstrato, colocando, então, como tarefa, a destruição da pseudoconcreticidade em busca da 
realidade concreta como reflexo da relação dinâmica do fenômeno com a essência. Busca-se dominar "a realidade social como unidade dialética de base e de superestrutura, e o homem como sujeito objetivo, histórico-social” (KOSIK, 2002, p. 52).

A construção da totalidade na organização das ideias concretas é fruto do pensar, da ação intelectiva do ser humano, mas não de sua elaboração meramente intuitiva, especulativa, pois parte da apropriação do mundo real.

A totalidade concreta como totalidade de pensamento, como um concreto de pensamento, é de fato um produto do pensar, do conceituar; mas de forma alguma é um produto do conceito que pensa fora e acima da intuição e da representação, e gera a si próprio, sendo antes produto da elaboração da intuição e da representação em conceitos. O todo como um todo de pensamentos, tal como aparece na cabeça, é um produto da cabeça pensante que se apropria do mundo do único modo que lhe é possível, um modo que é diferente de sua apropriação artística, religiosa e prático-mental. O sujeito real, como antes, continua a existir em sua autonomia fora da cabeça; isso, claro, enquanto a cabeça se comportar apenas de forma especulativa, apenas teoricamente. Por isso, também no método teórico o sujeito, a sociedade, tem de estar continuamente presente como pressuposto da representação. (MARX, 2011, p. 78-79)

A preocupação com a história na perspectiva marxista está relacionada à intervenção na práxis, no sentido de conhecer para transformar, de perceber o movimento do fenômeno em sua dinâmica de contradições, suas relações e modificações ao longo do tempo. A história é demarcada pelos conflitos da luta de classes, pelas contradições da vida social da humanidade - desigualdades, processos de exploração, apropriação e expropriação dos bens da natureza - e pelas revoluções sociais que "longe de ser extravios do bom caminho da história, não são senão os grandes momentos que, ao definirem o provisório resultado dos antagonismos sociais, marcam os momentos fundantes de seu deterioramento" (BORON, 2007, p. 37). Ainda, ao tentar falar dos aportes do marxismo para o estudo da sociedade, Borón (2007) definiu algumas premissas que caracterizam o método dialético, além de destacar três aportes que considera centrais no que se refere à racionalidade dialética organizada a partir da crítica à dialética hegeliana, expressando que: 1 . O conflito social é onipresente, 2. A lógica na história não é de identidade senão de contradição, e sua perspectiva é 3. Socialmente corrosiva e radical (BORON, 2007, p. 37-39).

Para a perspectiva marxista, os conflitos sociais demonstrados pela história estão presentes na sociedade com seus antagonismos e contradições de classes. Diferente de como situa o pensamento ideológico medieval e burguês que localizam o conflito social como um desajuste temporal à lógica do sistema, a visão dialética possibilita situar as contradições na história e confrontar seus fundamentos ideológicos. A história se constitui sobre o relato de um determinado modo de produção e na atualidade as contradições são resultantes da acumulação do capital. Diferentemente da concepção burguesa de história, localizada na lógica da identidade, sob o olhar linear e evolucionista que não abre espaço para rupturas radicais, caracterizada como uma sequência ordenada de acontecimentos, para o marxismo a história é impulsionada pela dinâmica das contradições, conflitos e revoluções sociais. O marxismo apresenta-se como socialmente corrosivo e radical por ser implacável com a perpetuação da sociabilidade capitalista, sendo por essência, crítico e radical, tratando a vida social sob os moldes capitalistas como fenômeno histórico possível de ser transcendido na luta de classes pelas camadas populares. 
Os três aportes centrais do marxismo elencados por Borón (2007) são: totalidade, historicidade e práxis. O primeiro deles, diz respeito à importância decisiva que Karl Marx atribui ao estudo da totalidade social concreta - em oposição às estéreis visões fragmentadoras e reificadoras das relações sociais que caracterizam o pensamento burguês, tanto nas suas versões convencionais quanto suas correntes "científicas" localizadas pontualmente nas ciências sociais, na sociologia, na ciência política e na economia. Os estudos da totalidade social ganharam importância em Marx em contraposição às elaborações burguesas com visões fragmentadas e reificadas das relações sociais, buscando "encontrar os termos exatos da relação dos elementos múltiplos e diversos que constituem a totalidade social entre si e com o todo do qual formam parte (BORON, 2007, p. 44). O segundo, destaca que o marxismo se propõe a elaboração teórica que recupere a complexidade e historicidade do social, confrontando as ideias burguesas de que a história chegou ao fim pela economia de mercado e democracia liberal, como também levantando a crítica ao positivismo que torna a se apresentar nas ciências sociais sob novas aparências. Por fim, o terceiro aporte enuncia a relação entre a teoria e a práxis como importante articulação para o nexo teoria/prática, assinalando a necessidade de o conhecimento estar alinhado à prática política e aos sentidos de transformação social.

Feitas estas considerações gerais e preliminares, passamos agora a tratar do objeto de estudo que motivou a elaboração deste artigo: identificar as contribuições dos métodos de investigação e exposição de viés marxista para a pesquisa no campo educacional.

\section{Os métodos de investigação e exposição na perspectiva do materialismo dialético}

Veremos, nesta parte, como o materialismo dialético trabalha com os métodos de investigação e de exposição, em dois momentos diferentes da pesquisa, mas que se complementam e dialogam para a construção da pesquisa em seu conjunto no processo de compreensão da realidade. Enquanto um significa um esforço prévio de apropriação analítica de determinações e conteúdo, o outro articula essas apropriações de maneira crítica com base nas contradições.

A perspectiva do método marxista funde os métodos analítico (investigação) e sintético (exposição), captando o que havia de essencial em cada um: por um lado a apropriação geral da natureza e por outro lado a singularidade do movimento histórico do objeto. Assim, os fenômenos são abordados nas perspectivas analítica e sintética. A abordagem analítica divide a realidade complexa em partes de complexidade menor. Quando enriquecido o conhecimento dessas partes, o pesquisador faz o caminho de volta, iniciando a abordagem sintética, articulando as partes de forma conceituadas e logicamente determinadas (FERNANDES, 2008).

Como as coisas não se mostram ao homem diretamente tal qual são e como o homem não tem a faculdade de ver as coisas diretamente na sua essência, a humanidade faz um detóur para conhecer as coisas e a sua estrutura. Justamente porque tal detóur é o único caminho acessível ao homem para chegar à verdade, periodicamente a humanidade tenta poupar-se o trabalho desse desvio e procura observar diretamente a essência das coisas (o misticismo é justamente a impaciência do homem em conhecer a verdade). Com isso corre o perigo de perder-se ou de ficar no meio do caminho, enquanto percorre tal desvio. (KOSIC, 2002, p. 27, itálico do original) 
A investigação está ligada a apropriação fatual da matéria a partir de fontes que possibilitem conhecer em detalhes as formas de desenvolvimento e as conexões internas para então passar a exposição e apresentar a reprodução ideal da matéria (GORENDER, 2013).

A elaboração do momento de exposição é uma elaboração do pensamento, mas uma composição estruturada com base no modo de produção. Marx "não nega, de maneira nenhuma, o momento em que o real, a partir do próprio real, deva ser pensado, concebido, reproduzido por meio do pensamento, isto é, reconstruído pelo pensamento como concreto pensado" (CHAGAS, 2011, p. 68).

Ao tratar sobre o método da economia política, Marx mostra que ao se começar por uma representação caótica do todo, não devemos estacionar nas determinações abstratas gerais como fizeram os economistas do século XVII, mas temos sim que fazer a "viagem de retorno", portanto, partir da representação caótica do todo, caminhar analiticamente para conceitos abstratos mais simples e então voltar a representação caótica inicial, mas dessa vez percebida em ricas determinações.

Se eu começasse pela população, esta seria uma representação caótica do todo e, por meio de uma determinação mais precisa, chegaria analiticamente a conceitos cada vez mais simples; do concreto representado [chegaria] a conceitos abstratos [Abstrakta] cada vez mais finos, até que tivesse chegado às determinações mais simples. Daí teria de dar início à viagem de retorno até que finalmente chegasse de novo à população, mas desta vez não como a representação caótica de um todo, mas como uma rica totalidade de muitas determinações e relações. (MARX, 2011, p. 77)

O todo dado imediatamente é caótico e sua compreensão é feita através da mediação das partes (KOSIK, 2002). A realidade caótica e complexa é dividida em partes de menos complexidade e depois volta para o todo de complexo maior.

O progresso da abstratividade à concreticidade é, por conseguinte, em geral, movimento da parte para o todo e do todo para a parte; do fenômeno para a essência e da essência para o fenômeno; da totalidade para a contradição e da contradição para a totalidade; do objeto para o sujeito e do sujeito para o objeto. (KOSIK, 2002, p. 37)

O ponto de partida é o simples historicamente, o fato ou fenômeno social como ele se reproduz em sua aparência. A análise então adentra a conhecer suas relações de interações e contradições (ENGELS, 2008). A interpretação da realidade é a compreensão de seu movimento. “A realidade é interpretada não mediante a redução a algo diverso de si mesma, mas explicando-a com base na própria realidade, mediante o desenvolvimento e a ilustração das suas fases, dos momentos do seu movimento” (KOSIK, 2002, p. 35). Mas o ponto de partida é também o ponto de chegada.

O ponto de partida do exame deve ser formalmente idêntico ao resultado. Este ponto de partida deve manter a identidade durante todo o curso do raciocínio visto que ele constitui a única garantia de que o pensamento não se perderá no seu caminho. Mas o sentido do exame está no fato de que no seu movimento em espiral ele chega a um resultado que não era conhecido no ponto de partida e que, portanto, dada a identidade formal do ponto de partida e do resultado, o pensamento, ao concluir o seu movimento, chega a algo diverso - pelo seu conteúdo - daquilo de que tinha partido. (KOSIK, 2002, p. 36)

A realidade em movimento, contraditória e histórica, necessita de sucessivas aproximações de idas e vindas entre o particular e o geral, o fenômeno e a essência, o objeto e o sujeito para sua compreensão (ARAÚJO, 2003). No percurso de análise o caminho é desenhado pela história, como aponta Marx: 
O dinheiro pode existir, e existiu historicamente, antes que exista o capital, antes que existam os bancos, antes que exista o trabalho assalariado etc. A partir desse ponto de vista, portanto, pode ser dito que a categoria mais simples pode expressar relações dominantes de um todo ainda não desenvolvido, ou relações subordinadas de um todo desenvolvido que já tinham existência histórica antes que o todo se desenvolvesse no sentido que é expresso em uma categoria mais concreta. Nesse caso, o curso do pensamento abstrato, que se eleva do mais simples ao combinado, corresponderia ao processo bistórico efetivo. (MARX, 2011, p. 80, grifo nosso)

O trabalho de investigação significa a maturação do objeto, observação de seus detalhes, formas de evolução e conexões internas (CHAGAS, 2011). Nesse momento, o objeto é captado nas múltiplas dimensões singulares e específicas, na relação mediata e imediata com a totalidade mais ampla, nas contradições, enfim, nas leis que estruturam o fenômeno (FRIGOTTO, 2010).

Segundo Kosik (2002, p. 37), a investigação compreende a "minuciosa apropriação da matéria, pleno domínio do material, nele incluídos todos os detalhes históricos aplicáveis, disponíveis", "análise de cada forma de desenvolvimento do próprio material", e "investigação da coerência interna, isto é, determinação da unidade das várias formas de desenvolvimento”.

Pensando a ciência como uma criação humana, como escreveu Gamboa (2010), a produção científica é fruto da práxis social dos seres humanos e serve para mediar a relação do homem com a natureza, do sujeito com o objeto, onde o pesquisador utiliza da teoria e da prática, da reflexão e da ação para a transformação da natureza. No caso da perspectiva do método marxista, há um conjunto de categorias articuladas em totalidade para reconstruir o mundo real através do pensamento, mas determinado socialmente, em que o limite não está no conhecer, mas em se propor a transformar.

Diante do movimento histórico das relações sociais de produção surgem as categorias, que são expressões de produtos históricos e transitórios.

(...) a categoria econômica mais simples, digamos, o valor de troca, supõe a população, população produzindo em relações determinadas; [supõe] também um certo tipo de família - ou comunidade - ou de Estado etc. Não pode jamais existir, exceto como relação abstrata, unilateral, de um todo vivente, concreto, já dado. Como categoria, ao contrário, o valor de troca leva uma vida antediluviana. Por essa razão, para a consciência para a qual o pensamento conceitualizante é o ser humano efetivo, e somente o mundo conceituado enquanto tal é o mundo efetivo - e a consciência filosófica é assim determinada -, o movimento das categorias aparece, por conseguinte, como o ato de producão efetivo que, infelizmente, recebe apenas um estímulo do exterior -, cujo resultado é o mundo efetivo (...). (MARX, 2011, p.78, grifo nosso)

As categorias de análise são construídas mediante as relações que determinam o fenômeno. São resultados do olhar do investigador sobre o fenômeno em sua complexidade e movimento real.

Nesse percurso, vamos intuindo, percebendo, conhecendo seu movimento e identificando as categorias mais complexas, que representam relações mais complexas, pois determinadas por outros processos, o que não nos permite conhecê-las senão da descoberta de suas determinações. Assim, chegamos as categorias mais simples, que são determinantes para a compreensão das categorias complexas. Só então, de posse dessas categorias mais simples, vamos realizando o caminho de volta, chegando às determinações mais complexas, o que nos possibilita a apropriação do real, na sua totalidade, como concreto pensado, que é o ponto de chegada do pesquisador. (ARAÚJO, 2003, p. 270) 
No materialismo histórico-dialético, as categorias são conceitos básicos que refletem o fenômeno em seus aspectos individual, particular e geral; causa e efeito; necessidade e causalidade; essência e aparência; conteúdo e forma; possibilidade e realidade, estando todas elas relacionadas umas com as outras (RICHARDSON, 1999). Se elas refletem o fenômeno de maneira multifacetada, temos que reconhecer que elas também são históricas.

Na obra intitulada Miséria da Filosofia: respostas à Filosofia da Miséria, do Sr. Proudhon (redigida em francês e publicada em 1847), Karl Marx vai descrever as determinações teóricas e metodológicas que acompanharão a sua produção científica até seus últimos dias. É neste texto que as considerações de ordem metodológica iniciadas com a colaboração de Friedrich Engels em $A$ ideologia alemã (escrita a quatro mãos entre os anos 1845 e 1846) avançam em termos conceituais, ao ponto de ampliar e dotar de uma melhor fundamentação àquela metodologia que a tradição marxista denominou como materialismo histórico. Mesmo que a crítica à economia política proposta por Marx (2017) tenha evoluído, sua formulação ainda tem muito que avançar em termos quantitativos e qualitativos, já que as proposições metodológicas de Miséria da Filosofia (2017) ainda estão longe de alcançar o rigor teórico-metodológico presente n’O Capital (2013a).

Buscando se contrapor às ideias reformistas propostas por Proudhon naquela época, Marx afirma que "As categorias econômicas são apenas expressões teóricas das relações sociais de produção" (MARX, 2017, p. 101). Logo, se as relações sociais de produção estão diretamente relacionadas às forças produtivas, cabe reconhecer que a cada mudança do modo de produção também mudam as relações sociais, já que:

Adquirindo novas forças produtivas, os homens mudam seu modo de produção e, ao mudar o modo de produção, a maneira de ganhar a vida, eles mudam todas as suas relações sociais. O moinho movido pelo braço humano nos dá a sociedade com o suserano; o moinho a vapor nos dá a sociedade com o capitalista industrial. (MARX, 2017, p. 102)

Em decorrência das mudanças supracitadas, Marx (2017) deixa claro a natureza histórica da categoria, diretamente vinculada ao objeto de estudo que a concebe, que a gera, ao mesmo tempo que ela também se torna transitória, pois:

\footnotetext{
Os mesmos homens que estabeleceram as relações sociais de acordo com sua produtividade material produzem também os princípios, as ideias, as categorias, de acordo com suas relações sociais.

Assim, essas ideias, essas categorias, são tão pouco eternas quanto as relações que elas exprimem. Elas são produtos históricos e transitórios.

Há um movimento contínuo de crescimento nas forças produtivas, de destruição nas relações sociais, de formação nas ideias; de imutável só existe a abstração do movimento - mors immortalis. (MARX, 2017, p. 102)
}

No método de exposição temos a explicitação do fenômeno que se apresenta de maneira mais compreensível. Esse momento é marcado pela crítica, onde o objeto reconstruído criticamente pelo pensamento espelhado no movimento real, é a reprodução do movimento efetivo da realidade (CHAGAS, 2011).

No processo dialético de conhecimento da realidade, o que importa fundamentalmente não é a crítica pela crítica, o conhecimento pelo conhecimento, mas a crítica e o 
conhecimento crítico para uma prática que altere e transforme a realidade anterior no plano do conhecimento e no plano histórico-social. (FRIGOTTO, 2010, p. 89)

O processo de compreensão e reprodução da realidade concreta perspectivada no conhecer para transformar, baseia-se na relação dialética entre teoria e prática, como assinala Gamboa (2012):

O retorno ao ponto de partida será mais rico e compreensivo. Tal concepção toma como base a estreita relação dialética entre a 'teoria e a prática'. Segundo a filosofia da práxis, só entendemos a teoria como 'teoria de uma prática' e vice-versa, a prática sempre é 'prática de uma teoria'. A teoria é entendida como a compreensão da prática. É elaborada a partir da prática e, uma vez analisada e compreendida, deve voltar sobre esta em forma de estratégias de ação. Desta maneira, cumpre-se um circuito em que o conhecimento parte da prática e volta sobre ela mesma, estabelecendo, dessa forma, um critério de verdade que exige uma tensão dialética entre esses dois polos contrários. Uma teoria é válida à medida que transforma a prática, e a prática também é verdadeira à medida que transforma a teoria. Dessa relação dialética surge o princípio da validade do conhecimento como fonte de transformação da realidade: 'conhecer para transformar'. (GAMBOA, 2012, p. 131-132)

$\mathrm{Na}$ exposição, a realidade deve ser apresentada de maneira lógica e coerente, de forma consciente e organizada pela interpretação dos resultados no processo de investigação (KOSIK, 2002; FRIGOTTO, 2010). As partes que compõem o objeto são articuladas de maneira que reconstituam o todo orgânico, mas não como somatório de justaposição mecânica, as categorias devem ser organizadas de acordo com as relações internas de determinações essenciais, na produção de um conhecimento a nível categorialsistemático (GORENDER, 2013).

A realidade expressa enquanto concreto pensado é o resultado de todo o processo, síntese de múltiplas determinações.

O concreto é concreto porque é a síntese de múltiplas determinações, portanto, unidade da diversidade. Por essa razão, o concreto aparece no pensamento como processo da síntese, como resultado, não como ponto de partida, não obstante seja o ponto de partida efetivo e, em consequência, também o ponto de partida da intuição e da representação. (MARX, 2011, p. 77-78)

O materialismo dialético possibilita elucidar os processos que envolvem a educação em suas relações na sociedade, contribuindo na compreensão da dinâmica e das contradições em que está imersa.

Todo fenômeno deve ser entendido como parte de um processo histórico maior. No caso da educação, suas transformações estão relacionadas com as transformações culturais e sociais. Sua dinâmica depende das mudanças sociais. Essas mudanças são qualitativas e quantitativas, à medida que se acumulam forças e tensões que produzem transformações radicais e estruturais (metamorfoses). (GAMBOA, 2012, p. 128)

Nas pesquisas de caráter crítico marxista a interação estabelecida entre diversas organizações que compõem a sociedade poderá possibilitar uma conjuntura mais favorável para a perspectiva transformadora.

Nas abordagens críticas, dada a primazia das relações entre educação e sociedade, as ações possíveis no campo educativo se realizam em função da sociedade com a qual estabelece interações. Essas interações serão tanto mais transformadoras quanto maior o grau de articulação com outras formas da organização social (movimentos da sociedade civil, organizações de classe, partidos políticos, sindicatos etc.). A articulação desses movimentos pode construir uma conjuntura favorável para a transformação dos sistemas educativos, à medida que a correlação de forças permita acumular uma massa crítica capaz de resistir às forças repressivas e desmobilizadoras e favoreça a preparação de novas ações, buscando fortalecer os movimentos emancipadores. (GAMBOA, 2012, p. 129) 
Para uma maior aproximação com a prática da pesquisa utilizando os princípios norteadores do materialismo dialético nas perspectivas dos métodos de investigação e exposição, apresentaremos contribuições dos professores Saviani (2018) e Frigotto (2010). O professor Saviani (2018, p. 3-4) na introdução do livro História das Ideias Pedagógicas no Brasil, coloca alguns princípios a respeito do método de investigação, a saber: "Caráter concreto do conhecimento histórico-educacional", "Perspectiva de "longa duração", "Olhar analítico-sintético no trato com as fontes", "Articulação do singular e do universal no exame das fontes", e "Atualidade da pesquisa histórica".

O primeiro princípio "Caráter concreto do conhecimento histórico-educacional” conceitua que o conhecimento histórico-educacional obedece ao movimento que considera o fenômeno educacional a partir de sua aparência caótica, perpassando a análise elaborada no pensamento, articulada em categorias advindas do próprio fenômeno, sendo, a posteriori, reproduzida criticamente pelo sujeito com riqueza de determinações que elucida o fenômeno educacional em sua totalidade.

O segundo princípio "Perspectiva de 'longa duração" está relacionado a uma orientação metodológica gramsciana que se expressa na importância de revelar os movimentos estruturais a partir de uma análise de períodos relativamente longos. Segundo Gamboa (2012, p. 128), "para se compreender as inter-relações sociais e as dinâmicas de tempos longos é preciso recuperar dados que permitam ver o movimento histórico, a gênese e a transformação dos fenômenos".

O terceiro princípio "Olhar analítico-sintético no trato com as fontes" está ligado à maneira como serão tratadas as informações reveladas pelas fontes, correspondendo a uma abrangência de diversidade e articulação sincrônica e diacrônica para que não se perca nenhuma característica do fenômeno.

O quarto princípio “Articulação do singular e do universal no exame das fontes” se refere à relação entre o singular e o universal no processo de investigação, às perspectivas locais, nacionais e internacionais que se revelam no fenômeno educacional. A importância desse momento é revelar a relação de reciprocidade, determinação ou subordinação existente entre as diferentes localidades.

Por fim, o quinto princípio “Atualidade da pesquisa histórica” aponta para o caráter de intenção existente no procedimento de investigação, pois não se trata de um processo neutro, mas de um evento imerso no presente, motivado por indagações da realidade conectado à dinâmica histórica vivida.

Sem a intenção de determinar uma regra geral a ser seguida, mas com o intuito de exemplificar no plano prático o desenvolvimento da atividade de pesquisa, Frigotto (2010, p. 96-98) elenca cinco movimentos fundamentais:

1. Partir de condições já dadas, definindo a problemática e delineando os objetivos, as concepções do investigador sobre o que se apresenta e os sujeitos aos quais a pesquisa se refere;

2. Resgatar teoricamente o que já foi produzido sobre a problemática para revisitar as ideias, conceitos e categorias no sentido de ruptura ou inclusão para superação;

3. Definir qual método será utilizado na análise e na exposição, isto é, na discussão dos conceitos e das categorias de interpretação dos dados; 
4. Analisar os dados, ou seja, estabelecer as conexões, mediações e contradições dos fatos da problemática;

5. Momento de elaboração e exposição da síntese da pesquisa, expondo de maneira orgânica, coerente e concisa as diversas determinações que explicam a problemática e discutem as implicações para a ação concreta.

Encerramos este tópico com as contribuições imprescindíveis dos professores Dermeval Saviani (2018) e Gaudêncio Frigotto (2010) com a intenção de apontar, em síntese, a práxis da pesquisa orientada nos princípios do materialismo histórico-dialético a partir de referenciais teóricos genuinamente brasileiros e pertencentes ao campo educacional. Uma vez apresentado nosso ponto de vista sobre as questões metodológicas, objeto de estudo deste artigo, trazemos as Considerações Finais, que foram desdobradas em dois momentos: o primeiro traz uma síntese dos resultados deste estudo; o segundo, uma apresentação dos problemas ainda em aberto, passíveis de serem aprofundados em futuras pesquisas pelos próprios autores ou por outros autores que queiram somar esforços e contribuir para a produção de conhecimento científico vinculado ao método de pesquisa objeto deste estudo.

\section{Considerações Finais}

A intenção principal deste artigo foi trazer contribuições para a compreensão do método marxista de pesquisa, nos aproximando do processo elucidativo dos métodos de investigação e exposição constitutivos da perspectiva do materialismo dialético. No primeiro momento apresentamos o contexto em que se desenvolveu o estudo, o objetivo - encontrar nos métodos de investigação e exposição contribuições para o desenvolvimento das pesquisas no campo educacional -, a metodologia utilizada e alguns elementos que consideramos importantes para introduzir as reflexões a respeito do método marxista.

Afirmamos que o método elaborado por Marx não é um tema que foi desenvolvido de forma intencional e objetiva pelo autor em uma determinada obra, mas um estudo mais apurado nos permite identificar seus fundamentos, distribuídos em textos diversos, de modo que podemos visualizar uma série de princípios teóricos e as trilhas metodológicas utilizadas por ele na hora da elaboração de seus escritos. Também alertamos para a consideração de que Marx não teve a intenção de apresentar sua proposta como se fosse uma receita pronta para o processo de investigação, já que as proposições apresentadas por ele contribuiriam mais com uma aproximação reflexiva a respeito do método.

Situamos o método em Marx como uma possibilidade de superação a outras perspectivas, sem descartá-las, mas como uma propositura de síntese, junção e complementação. Um dos caminhos apontados e aqui valorizados foi a importância da decomposição do todo para compreensão das partes, entendendo que esse todo significa as articulações e os movimentos relacionados ao fenômeno estudado, na busca pela superação da pseudoconcreticidade, para alcançar a essência do fenômeno e revelar o seu processo de reprodução social na visão do senso comum, a fim de superar essa aparência. Outro elemento importante da perspectiva marxista aqui ressaltado é a consideração do enredo histórico, uma vez que a elaboração 
teórica não serve apenas para descrever a realidade como ela se processa, mas no sentido de intervir nesse processo histórico e contribuir para a superação das suas contradições.

$\mathrm{Na}$ busca de respostas à questão norteadora aviltada (Quais as contribuições dos métodos de investigação e exposição de viés marxista para a pesquisa no campo educacional?), visualizamos muitas contribuições que podem inferir a essa questão, pois as colaborações que o método em Marx nos coloca para compreensão da realidade e a produção do conhecimento são muito significativas. As colocações já apontadas nos permitem afirmar incialmente, que o método em Marx nos orienta primeiramente a analisar o fenômeno educativo em questão para depois lançar nota de sua síntese, fazendo dois caminhos em um mesmo processo, um de ida, revelando as categorias, as contradições e os complexos articulados ao fenômeno e outro de volta, reconstruindo esse fenômeno que antes se apresentava de maneira desalinhada, de difícil compreensão, para apresentar uma aparência mais elucidada de suas determinações históricas. Portanto, é através do método de investigação que podemos conhecer as conexões internas do objeto de estudo, iniciando por sua representação confusa, procurando explicar suas determinações histórico-sociais através da mediação das partes que compõem o todo caótico. São várias as idas e vindas no processo de investigação, sendo o percurso desenhado pela história. É no desenvolvimento da investigação que surgem as categorias, construídas nas relações que determinam o fenômeno.

O método de exposição traz como ponto de chegada, exatamente o ponto de partida, o mesmo fenômeno em questão, mas ele já não se apresenta de forma desordenada, mas se expõe com suas determinações criticamente reveladas. O procedimento crítico é um marco importante do método e se coloca ao sentido de conhecer para transformar. $\mathrm{Na}$ exposição, a realidade é apresentada de maneira lógica e coerente, consciente e organizada, sendo o concreto pensado, resultado de múltiplas determinações.

No intuito de aproximar a compreensão do processo de desenvolvimento dos métodos de investigação e exposição, nos valemos dos aportes teóricos e princípios metodológicos propostos por Saviani na obra História das ideias pedagógicas no Brasil (2018). Nessa obra encontramos uma bem-elaborada proposta, descrita na forma de princípios, que servem para fundamentar o método de exposição na perspectiva do materialismo histórico e dialético. Partindo da realidade educacional concreta, o autor articula o fenômeno educativo em sua totalidade, sempre atento às perspectivas de organização histórica, sincrônica e diacrônica, às articulações em diferentes localidades e ao compromisso da pesquisa na intervenção da realidade, já que ela não possui o caráter de neutralidade.

Por outro lado, no trabalho do professor Frigotto (2010), encontramos considerações a respeito de momentos fundamentais da pesquisa, iniciada pela apropriação das condições reais em que se encontra o objeto de estudo, a revisão da literatura a respeito do que já se tem produzido sobre os fenômenos em questão, a definição do método, e a análise dos dados, o que nos remete ao método de investigação enquanto perspectiva analítica do objeto e o momento de síntese que aponta para a exposição do estudo de maneira orgânica, coerente, concisa e diversa no conjunto de elementos de determinação para a compreensão do problema de pesquisa, bem como as implicações de intervenção e continuidade dos estudos. 
Nas últimas linhas deste artigo também queremos tecer algumas considerações a respeito do texto escolhido para a epígrafe deste artigo. Trata-se dos últimos parágrafos de Miséria da Filosofia (2017), onde Karl Marx deixa explicita a essência revolucionária da sua proposta. Em convite à militância em favor da transformação social e da superação das históricas desigualdades que caracterizam as sociedades divididas em classes, Marx (2017) deixa às claras a unicidade entre o movimento social e o movimento político e viceversa para podermos, com o auxílio da ciência social, superar o antagonismo de classe e a reorganização geral da sociedade, ou seja, a ciência posta a favor da transformação social. A ciência posta a favor da revolução social, de modo que “....a ciência produzida pelo movimento histórico, e associando-se a ele com pleno conhecimento de causa, deixa de ser doutrina e se torna revolucionária” (MARX, 2017, p. 113).

Ressaltamos, ainda, a importância de conhecermos e nos apropriarmos dos fundamentos que orientam o método de investigação materialista dialético para a consolidação de pesquisas no campo educacional. Esperamos que este texto possa contribuir para uma aproximação e uma compreensão dos métodos de investigação e de exposição em Karl Marx - objetivo proposto pelos seus autores, bem como colaborar na formação de pesquisadores da classe trabalhadora e dos movimentos sociais. Somos cientes que se trata de um tema que não está isento de dificuldades, pois ele é complexo e multifacetado. Fiel à tradição marxista, se trata de uma construção crítica e coletiva, que precisa da contribuição de outros pesquisadores identificados com este método e de mais estudos e pesquisas de aprofundamento. Importa, pois, também salientar, que não se pretendeu aqui esgotar o tema, mas sim oferecer um aporte teórico que possa vir a subsidiar estudos futuros de outros autores no campo educacional.

\section{Referências}

ARAUJO, L. B. de C. A questão do método em Marx e Lukács: o desafio da reprodução ideal de um processo real. In: MENEZES, A. M. D. de (org.). Trabalho, sociabilidade e educação: uma crítica à ordem do capital - Fortaleza: Editora UFC, 2003.

BORON, A. A. Aula Inaugural. Pelo necessário (e demorado) retorno ao marxismo. In: BORON, A. A.; AMADEO, J.; GONZÁLEZ, S. (orgs.). A teoria marxista hoje. Problemas e perspectivas. Buenos Aires: CLACSO (Consejo Latinoamericano de Ciencias Sociales), 2007. P. 29-47. Disponível em: http://biblioteca.clacso.edu.ar/clacso/formacion-virtual/20100715073000/boron.pdf. Acesso em: 04 mai. 2020.

CHAGAS, E. F. O método dialético de Marx: investigação e exposição crítica do objeto. Síntese Revista de Filosofia, Belo Horizonte, v. 38, n. 120, p. 55-70, 2011. Disponível em: http://www.faje.edu.br/periodicos/index.php/Sintese/article/view/1036. Acesso em: 11 mai. 2020.

DUAYER, M. Apresentação. In: MARX, K. Grundisse. Manuscritos econômicos de 1857-1858. Esboços da crítica da economia política. eBook Kindle. São Paulo: Boitempo, 2011. P. 15-32.

ENGELS, F. Comentários sobre a contribuição à crítica da economia política, de Karl Marx. In: MARX, K. Contribuição à crítica da economia política. $2^{\circ}$ ed. São Paulo: Expressão Popular, 2008. P. 273-285.

EVANGELISTA, J. E. Crise do marxismo e irracionalismo pós-moderno. $2^{\circ}$ ed. São Paulo: Cortez, 1997.

FELISMINO, C. A pesquisa na formação do educador. In: JIMENEZ, S. V.; RABELO, J. (orgs.).

Trabalho, educação e luta de classes: a pesquisa em defesa da história - Fortaleza- CE: Brasil Tropical, 2004. 
FERNANDES, F. Introdução. In: MARX, K. Contribuição à crítica da economia política. $2^{\circ}$ ed. São Paulo: Expressão Popular, 2008. P. 19-44.

FRIGOTTO, G. O enfoque da dialética materialista histórica na pesquisa educacional. In: FAZENDA, I. (org.). Metodologia da pesquisa educacional. 12º ed. São Paulo: Cortez, 2010. p. 75-100.

GAMBOA, S. S. A dialética na pesquisa em educação: elementos de contexto. In: FAZENDA, I. (org.). Metodologia da pesquisa educacional. $12^{\circ}$ ed. São Paulo: Cortez, 2010. p. 101-130.

GAMBOA, S. S. Pesquisa em educação: métodos e epistemologias. 2ºd. Chapecó: Argos, 2012.

GORENDER, J. Apresentação. In: MARX, K. O capital: Crítica da economia política. Livro I: o processo de produção do capital. eBook Kindle. São Paulo: Boitempo, 2013. P. 20-55.

HARVEY, D. Para entender o capital - Livro I. São Paulo: Boitempo, 2013.

KOSIK, K. Dialética do concreto. $7^{\circ}$ ed. Rio de Janeiro: Paz e Terra, 2002.

LOWY, M. Método dialético e teoria política. $2^{\circ}$ ed. Rio de Janeiro: Paz e Terra, 1989.

MARX, K.; ENGELS, F. A sagrada família ou A crítica da Crítica crítica contra Bruno Bauer e consorte. São Paulo: Boitempo, 2003.

MARX, K.; ENGELS, F. A ideologia alemã: crítica da mais recente filosofia alemã em seus representantes Feuerbach. B. Bauer e Stiner, e do socialismo alemão em seus diferentes profetas (18451846). São Paulo: Boitempo, 2007.

MARX, K. Contribuição à crítica da economia política. Tradução e introdução de Florestan Fernandes. $2^{\circ}$ ed. São Paulo: Expressão Popular, 2008.

MARX, K. Grundisse. Manuscritos econômicos de 1857-1858. Esboços da crítica da economia política. eBook Kindle. São Paulo: Boitempo, 2011.

MARX, K. O capital, volume 1. São Paulo: Boitempo, 2013a.

MARX, K. Crítica da filosofia do direito de Hegel. São Paulo: Boitempo, 2013b.

MARX, K. Miséria da filosofia. Resposta à Filosofia da Miséria, do Sr. Proudhon. São Paulo: Boitempo, 2017.

NETTTO, J. P.; BRAZ, M. Economia política: uma introdução crítica. $7^{\circ}$ ed. São Paulo: Cortez Editora, 2011.

RICHARDSON, R. J. Pesquisa social: métodos e técnicas. $3^{\circ}$ ed. São Paulo: Atlas, 1999.

SARTRE, J. P. Crítica da Razão Dialética. Tradução: Guilherme João de Freitas Teixeira. Rio de Janeiro: DP\&A, 2002.

SAVIANI, D. História das Ideias Pedagógicas no Brasil. $4^{\circ}$ ed. Campinas, SP: Autores Associados 2018.

TRIVIÑOS, A. N. S. Introdução à pesquisa em ciências sociais: a pesquisa qualitativa em educação. $5^{\circ}$ ed. São Paulo: Atlas, 2009.

\footnotetext{
Notas

${ }^{1}$ Mestre em educação pela Universidade Estadual do Ceará. Graduado em Educação Física na Universidade Federal de Pernambuco. Doutorando do Programa de Pós-Graduação em educação da Universidade Federal da Paraíba. Professor da Rede estadual de Educação da Paraíba. Integrante do Grupo de Estudos e Pesquisas Pedagogia Histórico-critica, Políticas Públicas e Mundo do Trabalho - membro do HISTEDBR Nacional dgp.cnpq.br/dgp/espelhogrupo/8978517205312220. Currículo Lattes: http://lattes.cnpq.br/4934976258594324.Orcid: http://orcid.org/0000-0002-1998-704X. E-mail: hdgsilva@yahoo.com.br
} 
2 Doutorado em Educação pela Universidade Estadual de Campinas (UNICAMP). Professor Titular da Universidade Federal da Paraíba (UFPB) e do Programa de Pós-graduação em Educação (PPGE), da UFPB. Líder do Grupo de Estudos e Pesquisas Pedagogia Histórico-critica, Políticas Públicas e Mundo do Trabalho - membro do HISTEDBR Nacional (dgp.cnpq.br/dgp/espelhogrupo/8978517205312220>). Atualmente Vice-coordenador do PPGE da UFPB. Currículo Lattes: http://lattes.cnpq.br/5339043311979485. $\quad$ Orcid: $\quad \underline{\text { http://orcid.org/0000-0003-1963-4639 }}$ E-mail: jorgefernandohermida@yahoo.com.br

${ }^{3} \mathrm{Na}$ sua obra clássica Crítica da razão dialética (2002), Sartre disserta magistralmente sobre a reunião proposta por ele entre existencialismo e marxismo. Isto é, sobre a necessária reunião do existencialismo à filosofia insuperável de nosso tempo - o marxismo (SARTRE, 2002). Para esse autor, o marxismo se constitui como o melhor caminho para a superação de toda e qualquer mazela vinculada à superação da ordem social burguesa na década dos anos 40 do século XX. Lembremos que nesse tempo o mundo foi marcado pela disputa entre o capitalismo e o socialismo, e o debate político pautou, na época, o tema da verdade em Marx e os caminhos para chegar ao comunismo.

4 Grupo de Estudos e Pesquisas “Educação, Políticas Públicas e Mundo do Trabalho”, liderado pelos profs. Dres. Jorge Fernando Hermida Aveiro (UFPB) e Jailton de Souza Lira (UFAL).

5 Tópicos em Políticas Educacionais I (2020.1), que teve como tema: Clássicos do marxismo (Marx, Engels, Gramsci e Mészáros), do Programa de Pós-graduação em Educação da Universidade Federal da Paraíba (PPGE/UFPB).

Recebido em: 14 jul 2021

Aprovado em: 08. nov. 2021 